\title{
Hubungan Kualitas Tidur Terhadap Konsentrasi Belajar Mahasiswa Fakultas Kedokteran Universitas Baiturahmah Padang Angkatan 2018
}

\author{
Djamalilleil S.F ${ }^{1}$, Rosmaini ${ }^{2}$, Dewi N.P \\ ${ }^{1}$ Mahasiswa Fakultas Kedokteran Unversitas Baiturrahmah Padang, Indonesia \\ Email: syarifahfazhilah@gmail.com \\ ${ }^{2}$ Bagian Histologi Fakultas Kedokteran Universitas Baiturrahmah Padang, Indonesia \\ Email: rosmainiadjasman48@gmail.com \\ ${ }^{3}$ Bagian Anatomi Fakultas Kedokteran Universitas Baiturrahmah Padang, Indonesia \\ Email: nadiapurnama.op@gmail.com
}

\begin{abstract}
Abstrak
Pendahuluan: Kurangnya kepedulian terhadap masalah kualitas tidur ini banyak dijumpai pada anak sekolahan, pekerja yang mempunyai jam terbang yang tinggi dan mahasiswa, dampak yang timbul akibat kurangnya tidur pada seseorang dapat mempengaruhi konsentrasi. Tujuan: untuk mengetahui hubungan kualitas tidur dengan konsentrasi belajar mahasiswa Fakultas Kedokteran Universitas Baiturrahmah Padang angkatan 2018. Metode: Ruang lingkup penelitian ini mencakup bidang ilmu kedokteran umum, Penelitian ini dilaksanankan di Fakultas kedokteran Universitas Baiturahmah Padang pada bulan April 2019 sampai Januari 2020. Jenis penelitian deskriptif analitik dengan desain penelitian cross sectional study. Populasi terjangkau pada penelitian adalah mahasiswa Fakultas Kedokteran Universitas Baiturahmah angkatan 2018 yang berjumlah 150 orang dengan 76 sampel dengan menggunakan teknik simple random sampling. Analisa data univariat disajikan dalam bentuk distribusi frekuensi dan persentase dan analisa bivariate menggunakan uji chi-square dan pengolahana data menggunakan komputerisasi program SPSS versi 24.0. Hasil: Berdasarkan hasil penelitian paling banyak memiliki kualitas tidur buruk yaitu 53 orang (69,7\%), paling banyak memiliki konsentrasi belajar buruk yaitu 42 orang $(55,3 \%)$ dan terdapat hubungan kualitas tidur dengan konsentrasi belajar mahasiswa Fakultas Kedokteran Universitas Baiturrahmah Padang angkatan 2018. $\mathrm{P}=0,034<0,05$. Kesimpulan: Kualitas tidur seseorang dapat mempengaruhi konsentrasi belajar mahasiswa Fakultas Kedokteran Universitas Baiturrahmah Padang angkatan 2018.
\end{abstract}

Kata Kunci: kualitas tidur, konsentrasi belajar, mahasiswa kedokteran angkatan 2018

\begin{abstract}
Introduction: The lack of concern toward sleep quality is frequently found on students of high schoold, hectic workers and college students, the impacts of sleep lack could affect to learning concentration. Aims: To find out the correlation between sleep quality and learning concentration, students of medical faculty, University of Baiturrahmah Padang in Second Year. Method: The scope of this study covers the field of general medical science, this study was conducted at the Faculty of Medical, University of Baiturahmah Padang on April 2019 to January 2020. The type of this study was descriptive analytic study with cross sectional study design. Affordable population in the study were students of the Faculty of Medical, University of Baiturahmah in second year, the amount was 150 people with 76 samples by using random sampling technique. Univariate data analysis was presented in the form of frequency and percentage distributions as well as bivariate analysis using chi-square test and data processing using computerized SPSS program version 24.0. Result: Based on the results of the study, People who had the poor sleep quality are 53 people (69.7\%), had a poor learning concentration are 42 people $(55.3 \%)$ and there was a correlation between sleep quality and learning concentration of students at the Faculty of Medical, University of Baiturrahmah, Padang in second year $P=$ $0.034<0.05$. Conclusion: It is proven that there was a correlation between sleep quality and the learning concentration of students at the Faculty of Medical, University of Baiturrahmah Padang, Second year.
\end{abstract}

Keywords: Sleep Quality, Learning Concentration, Medical Student Second Year

Health \&Medical Journal 


\section{Pendahuluan}

Kemampuan berkonsentrasi dapat menurun disebabkan karena tidak cukunya kebutuhan tidur. Dewasa muda yang mengalami hambatan dalam proses belajar disebabkan oleh rasa mengantuk dan lelah akibat kurang tidur, sehingga konsentrasi belajar menjadi menurun. Hal ini perlu mendapatkan perhatian yang serius karena gangguan tidur (sleep deprivation) dapat mempengaruhi proses belajar, gangguan memori dan kesehatan emosi. ${ }^{1}$

Tidur merupakan keadaan tidak sadar yang termasuk dalam salah satu kebutuhan dasar manusia. ${ }^{2,3}$ Kecukupan tidur ditentukan oleh faktor jam tidur (kuantitas tidur) dan kedalaman tidur (kualitas tidur). Kualitas tidur dikatakan baik jika tidak menunjukkan tanda-tanda kekurangan tidur dan tidak mengalami masalah dalam tidur. Kondisi kurang tidur banyak ditemukan pada kalangan dewasa muda terutama mahasiswa yang dapat menimbulkan banyak efek, seperti berkurangnya konsentrasi belajar dan gangguan kesehatan.

Dampak yang timbul akibat kurangnya tidur pada seseorang dapat mempengaruhi aspek memori dan konsentrasi. ${ }^{4}$ Konsentrasi yang dimaksudkan adalah memusatkan perhatian pada situasi belajar. Jika seseorang mengalami kesulitan konsentrasi, jelas belajarnya akan percuma, karena hanya membuang tenaga, waktu dan biaya. Seseorang yang dapat belajar dengan baik, ia harus memiliki kebiasaan untuk memusatkan pikiran. Semakin tinggi tingkat konsentrasi seseorang pada suatu kegiatan maka akan semakin sukses kegiatan yang di lakukannya. Sebaliknya, jika tingkat konsentrasi lemah maka akan menimbulkan aktivitas yang berkualitas rendah. ${ }^{4}$

National Sleep Foundation menemukan bahwa hampir $90 \%$ orang dewasa di Amerika Serikat dengan kesehatan tidur yang sangat baik merasa sangat efektif dalam menyelesaikan sesuatu setiap hari, dibandingkan dengan $46 \%$ dari mereka yang memiliki kesehatan tidur yang buruk. Studi ini juga menunjukkan bahwa hanya $10 \%$ orang dewasa Amerika yang memprioritaskan tidur mereka di atas aspek kehidupan sehari-hari lainnya seperti kebugaran, gizi, pekerjaan, kehidupan sosial, dan hobi. ${ }^{5}$

Kurangnya kepedulian terhadap masalah kualitas tidur ini banyak dijumpai pada anak sekolahan, pekerja yang mempunyai jam terbang tinggi dan mahasiswa. Kelompok yang paling tinggi risikonya untuk terkena gangguan tidur adalah mahasiswa terutama mahasiswa fakultas kedokteran. ${ }^{3}$

Survei indeks pola hidup sehat American International Assurance (AIA) pada tahun 2013 di Indonesia yang dilaksanakan oleh perusahaan riset global yaitu Taylor Nelson Sofrens (TNS) menunjukkan bahwa masyarakat Indonesia yang ingin mendapatkan waktu tidur selama 7-8 jam ternyata hanya dapat merealisasikan 6 jam saja setiap harinya karena aktivitas mereka yang semakin lama semakin meningkat. ${ }^{3}$

Peneliti telah melakukan survei awal kepada 10 orang mahasiswa regular angkatan 2018 di Fakultas Kedokteran Universitas Baiturahmah Padang. Berdasarkan hasil survei tersebut rata-rata mahasiswa memiliki kualitas tidur yang burukyaitu kurang dari 78 jam setiap harinya. ${ }^{6}$

\section{Metode Penelitian}

Penelitian ini dilaksanankan di Fakultas Kedokteran Universitas Baiturahmah Padang pada bulan April 2019 sampai Januari 2020.

Subjek penelitian adalah seluruh mahasiswa Fakultas Kedokteran Universitas Baiturahmah angkatan 2018. Subjek diminta mengisi kuesioner. memberikan kuesioner kepada responden. 
Analisis univariat ini dilakukan terhadap setiap variabel untuk melihat gambaran kualitas tidur dan konsentrasi belajar pada responden.

Analisa bivariat ini digunakan untuk menganalisis hubungan antara 2 (dua) variabel yaitu kualitas tidur dan konsentrasi belajar menggunakan Chi-Square dengan menggunakan program SPSS (Statistical Product and Service Solution). Bila nilai signifikansinya $\mathrm{p}<0,05$ maka terdapat hubungan antara variabel independen dengan variabel dependen. Bila nilai $\mathrm{p}>0,05$ maka tidak terdapat hubungan antara variabel independen dengan variabel dependen.

\section{III.Hasil Penelitian}

Distribusi frekuensi responden berdasarkan kualitas tidur pada mahasiswa Fakultas Kedokteran Universitas Baiturrahmah Padang angkatan 2018 yaitu:

TABEL 1.

DISTRIBUSI

FreKUENSI

RESPONDEN BERDASARKAN KUALITAS TIDUR PADA MAHASISWA FAKULTAS KEDOKTERAN UNIVERSITAS BAITURRAHMAH ANGKATAN 2018

\begin{tabular}{lcc}
\hline Kualitas Tidur & $\boldsymbol{f}$ & $\boldsymbol{\%}$ \\
\hline Baik & 23 & 30.3 \\
Buruk & 53 & 69.7 \\
\hline Jumlah & 76 & 100 \\
\hline
\end{tabular}

Berdasarkan tabel 1 diperoleh hasil dari 76 mahasiswa, sebanyak 53 orang mahasiswa memiliki kualitas tidur buruk berikut :

Tabel 2. Distribusi Frekuensi Responden Berdasarkan Konsentrasi Belajar PaDA MAHASISWA FAKULTAS KEDOKTERAN UNIVERSITAS BAITURRAHMAH ANGKATAN 2018

\begin{tabular}{lcc}
\hline Konsentrasi Belajar & $\boldsymbol{f}$ & \% \\
\hline Baik & 34 & 44.7 \\
Buruk & 42 & 55.3 \\
\hline Jumlah & 76 & 100 \\
\hline
\end{tabular}

Berdasarkan tabel 2 diperoleh hasil dari 76 mahasiswa paling banyak memiliki konsentrasi belajar buruk yaitu 42 orang $(55,3 \%)$.

\section{A. Analisa Bivariat}

Berikut ini disajikan hasil penelitian tentang hubungan kualitas tidur dengan konsentrasi belajar mahasiswa Fakultas Kedokteran Universitas Baiturrahmah Padang angkatan 2018 pada tabel dibawah ini:

Tabel 3. Hubungan Kualitas Tidur dengan KonSENTRASI BELAJAR MAHASISWA FAKUltas KEDOKTERAN UNIVERSITAS BAITURRAHMAH PADANG ANGKatan 2018

\begin{tabular}{|c|c|c|c|c|c|c|c|}
\hline \multirow{3}{*}{$\begin{array}{c}\text { Kualitas } \\
\text { Tidur }\end{array}$} & \multicolumn{4}{|c|}{ Konsentrasi belajar } & \multirow{2}{*}{\multicolumn{2}{|c|}{ Jumlah }} & \multirow{3}{*}{$\begin{array}{c}P \\
\text { Value }\end{array}$} \\
\hline & \multicolumn{2}{|c|}{ Baik } & \multicolumn{2}{|c|}{ Buruk } & & & \\
\hline & $f$ & $\%$ & $f$ & $\%$ & $N$ & $\%$ & \\
\hline Baik & 15 & 65,2 & 8 & 34,8 & 23 & 100 & \\
\hline Buruk & 19 & 35,8 & 34 & 64,2 & 53 & 100 & $\mathbf{0 , 0 3 4}$ \\
\hline Jumlah & 34 & 44,7 & 42 & 55,3 & 76 & 100 & \\
\hline
\end{tabular}

Berdasarkan tabel 3 diperoleh dari 23 mahasiswa dengan kualitas tidur baik dan juga memiliki konsentrasi belajar yang baik yaitu 15 orang $(65,2 \%)$ dan dari 53 mahasiswa dengan kualitas tidur buruk dan konsentrasi belajar yang juga buruk yaitu 34 orang (64,2\%). Hasil uji statistic (chi-square) diperoleh nilai $\mathrm{p}=0,034(\mathrm{p}<0,05)$, maka dapat disimpulkan bahwa terdapat hubungan kualitas tidur dengan konsentrasi belajar mahasiswa Fakultas Kedokteran Universitas Baiturrahmah Padang angkatan 2018.

\section{Pembahasan}

Berdasarkan penelitian diperoleh hasil dari 76 sampel mahasiswa Fakultas Kedokteran Universitas Baiturrahmah angkatan 2018 yang paling banyak memiliki kualitas tidur buruk yaitu 53 orang $(69,7 \%)$. Hasil penelitian ini didukung penelitian sebelumnya yang dilakukan oleh Fenny, (2016) diperoleh hasil paling banyak mahasiswa dengan kualitas tidur buruk yaitu sebesar $61,7 \%$. Hal ini juga d idukung oleh penelitian Arisandi, (2017) dengan hasil paling banyak kualitas tidur mahasiswa adalah buruk yaitu sebesar $65 \% .^{3,7}$ 
Kondisi responden pada Fakultas Kedokteran Universitas Baiturrahmah ini yang didominasi memiliki ganguan kualitas tidur buruk disebabkan oleh beberapa hal yaitu seperti rata-rata $9 \%$ responden bermain gadget hingga larut malam dikarenakan game dan sosial media dan $11 \%$ disesabkan oleh keadaan lingkungan disekitar tempat tinggal yang tidak nyaman karena seringnya terdengar suara berisik yang bersumber dari suara kendaraan dijalanan, suara tetangga maupun suara dari seng rumah. ${ }^{8}$

Responden yang juga merupakan mahasiswa aktif di Fakultas Kedokteran ini cenderung memiliki gangguan tidur pada saat sebelum ujian dan selama ujian modul berlangsung dikarenakan rata-rata $20 \%$ responden akan belajar hingga larut malam untuk persiapan ujian agar mendapatkan nilai yang maksimal. Selain ujian modul yang mereka hadapi, mereka juga diiringi dengan tugas yang menumpuk sehingga membuat rata-rata $34 \%$ responden merasa stress dan menjadi sulit untuk tidur karena memikirkan ujian modul dan tugas yang masih belum selesai dikerjakan. ${ }^{9}$

Kualitas tidur yang buruk ini disebabkan oleh tugas-tugas kuliah yang banyak dan jadwal kuliah yang padat akan menyebabkan mahasiswa kekurangan waktu untuk tidur. Jika di hubungkan dengan teori, usia 12-18 tahun memerlukan waktu tidur 8-9 jam per hari. Saat seseorang mencapai usia 18-40 tahun, mereka cenderung memerlukan waktu tidur 7-8 jam per hari. Sedangkan usia 40-60 cenderung memerlukan waktu 7 jam per hari dengan tidur siang yang lebih sering pada siang hari. ${ }^{10,11}$

Menurut National Sleep Foundation tahun 2006, kualitas tidur dapat dipengaruhi oleh berbagai faktor baik yang berasal dari dalam maupun dari luar diri seseorang. Beberapa faktor tersebut diantaranya adalah penyakit, kelelahan, stress emosional, motivasi, gangguan tidur, kondisi lingkungan, gaya hidup, stimulan dan alkohol, diet, merokok, dan lain sebagainya. ${ }^{12}$ Di sisi lain, Lai (2001) menyebutkan bahwa kualitas tidur ditentukan oleh bagaimana seseorang mempersiapkan pola tidurnya pada malam hari seperti kecukupan tidur dan kemudahan untuk tertidur tanpa adanya bantuan medis. Kualitas tidur yang baik dapat memberikan perasaan tenang di pagi hari, perasaan energik, dan tidak mengeluh akan gangguan tidur. Dengan kata lain, memiliki kualitas tidur baik sangat penting untuk hidup sehat semua orang. ${ }^{13}$

Menurut Sastrawan tahun 2017, usia responden yang termasuk dalam rentang usia remaja akhir. Rentang usia ini cenderung memiliki faktor risiko yang dapat mengganggu kualitas tidur. Usia remaja akhir sering kali memiliki kebiasaan mengkonsumsi makanan yang tidak sehat, konsumsi alkohol, merokok, keluar hingga larut malam, menonton film dan kebiasaan bermain game hingga begadang yang tentunya akan mempengaruhi kualitas tidur individu bersangkutan. Selain itu kondisi mental remaja akhir yang masih cenderung labil sering memicu terjadinya stress yang juga dapat mempengaruhi kualitas tidur. Terlebih lagi responden yang merupakan mahasiswa semester 3 memiliki kondisi penyesuaian sistem perkuliahan. Kondisi ini tentunya dapat menjadi stressor pada mahasiswa bersangkutan yang berdampak pada kualitas tidurnya. ${ }^{14}$

Kualitas tidur yang buruk dapat menyebabkan gangguan pada kesehatan, kualitas tidur yang baik seringkali terabaikan dan masih ada anggapan bahwa gangguan tidur ini bukan masalah yang serius. Padahal tidur merupakan kebutuhan yang penting bagi manusia. ${ }^{15}$ Kualitas tidur yang buruk memberi efek yang buruk diantaranya sakit kepala dan sulit berkonsentrasi, selain itu juga kurang tidur dapat mengganggu metabolisme tubuh. Seperti yang sudah diketahui tidur adalah proses pemulihan selsel tubuh. Jika proses ini terganggu tentu regenerasi sel-sel tubuh tidak akan maksimal 
akibatnya tubuh menjadi lemas dan rentan terhadap penyakit. ${ }^{16}$

Beberapa penelitian tersebut termasuk penelitian ini membuktikan bahwa kualitas tidur pada usia masa perkuliahan cenderung lebih buruk. Hal ini disebabkan oleh berbagai faktor eksternal yang dapat menyebabkan supresi dari pengeluaran melatonin yang pada akhirnya akan dapat menyebabkan gangguan tidur dan pada mahasiswa terutama mahasiswa kedokteran disebabkan oleh aktivitas perkuliahan mereka yang padat. $^{17}$

Berdasarkan penelitian diperoleh hasil dari 76 mahasiswa, paling banyak memiliki konsentrasi belajar buruk yaitu 42 orang $(55,3 \%)$ pada mahasiswa Fakultas Kedokteran Universitas Baiturrahmah angkatan 2018.

Hasil penelitian ini sejalan dengan penelitian Rahmadi tahun 2017 dengan diperoleh hasil konsentrasi belajar mahasiswa yang buruk yaitu sebanyak 58,8\%. Penelitian yang dilakukan oleh Sastrawan tahun 2017 juga menunjukkan bahwa paling banyak konsentrasi belajar mahasiswa yang buruk yaitu sebanyak $77 \%$. ${ }^{18,8}$

Daya konsentrasi dapat dipengaruhi oleh berbagai faktor yang berasal dari luar maupun dalam diri seseorang. Faktor dari luar erat kaitannya dengan keadaan lingkungan sekitar. Adanya rangsangan yang mencolok, suara keras, keramaian dan lain sebagainya tentunya dapat mengganggu daya konsentrasi seseorang. Sedangkan faktor dari dalam diri meliputi usia, kondisi psikologis dan kondisi fisiologis. ${ }^{19}$ Adanya konsentrasi pada saat belajar akan membuat seseorang merasa senang mengikuti proses pembelajaran sehingga materi yang diterima akan mudah untuk di pahami. Seseorang yang memiliki konsentrasi belajar yang baik tidak akan mudah mengalihkan perhatiannya pada hal lain yang tidak ada hubungannya dengan materi tersebut. ${ }^{20}$ Seseorang dengan konsentrasi belajar yang baik akan memperoleh hasil yang maksimal dan baik buruknya prestasi yang dicapai seseorang juga dipengaruhi oleh konsentrasi belajarnya. $^{21}$

Berdasarkan penelitian diperoleh hasil dari 23 mahasiswa yang memiliki kualitas tidur baik lebih banyak memiliki konsentrasi belajar juga baik yaitu 15 orang $(65,2 \%)$ dan dari 53 mahasiswa dengan kualitas tidur buruk lebih banyak memiliki konsentrasi belajar buruk yaitu 34 orang $(64,2 \%)$. Hasil uji statistic (chi-square) diperoleh nilai $\mathrm{p}=0,034(\mathrm{p}<0,05)$, maka dapat disimpulkan bahwa terdapat hubungan kualitas tidur dengan konsentrasi belajar mahasiswa Fakultas Kedokteran Universitas Baiturrahmah Padang angkatan 2018.

Tingkat konsentrasi belajar mahasiswa dipengaruhi oleh faktor internal (faktor yang berasal dari dalam diri seseorang) dan faktor eksternal (faktor yang berasal dari luar) yang dapat meningkatkan konsentrasi belajar seseorang. Faktor internal dapat berupa kondisi fisiologis seperti kualitas tidur yang buruk. Kualitas tidur yang buruk dapat menimbulkan manifestasi klinis seperti mengantuk dan kelelahan yang dapat menurunkan energi seseorang saat menjalani aktivitas pada siang hari. Mengantuk dan kelelahan juga dapat menyebabkan ketidakmampuan seseorang untuk berkonsentrasi. $^{2,22}$

Penelitian ini sejalan dengan penelitian sebelumnya yang dilakukan oleh Rahmadi tahun 2017 yang menunjukkan bahwa terdapat hubungan antara kualitas tidur terhadap konsentrasi mahasiswa Fakultas Kedokteran Universitas Muhammadiyah Palembang $(p=0,02<0,05)$. Hal ini didukung oleh penelitian Sastrawan tahun 2017 pada mahasiswa program Studi Pendidikan Dokter Fakultas Kedokteran Universitas Udayana diperoleh hasil terdapat hubungan antara kualitas tidur terhadap konsentrasi belajar dengan nilai $\mathrm{p}<0,05$. $^{18,8}$ 
Penelitian ini berbeda dengan penelitian yang dilakukan oleh Agista Dewi Maulina pada tahun 2016 yang menunjukkan bahwa tidak terdapat hubungan antara kualitas tidur dengan daya konsentrasi pada mahasiswa tingkat empat Fakultas Kedokteran Universitas Islam Bandung dengan ( $\mathrm{p}>0,05)$. Hal ini dikarenakan daya konsentrasi tidak hanya dipengaruhi oleh kualitas tidur, namun juga dapat disebabkan oleh berbagai faktor seperti proses adaptasi dan kebiasaan mahasiswa kedokteran yang terbiasa tidur larut malam dan tidak teratur sehingga dengan kualitas tidur yang buruk mahasiswa tersebut masih dapat berkosentrasi dengan baik. $^{21}$

Berdasarkan data dari kuesioner PSQI pada komponen 8 tentang daytime dysfunction yang telah diisi oleh responden, ditemukan hasil bahwa responden dengan kualitas tidur yang buruk juga terganggu aktivitasnya di siang hari. Hal ini tentu saja dapat mempengaruhi aktivitas belajar responden dikampus karena aktivitas kampus yang lebih banyak dilakukan pada pagi hingga siang hari. Menurut survei yang dilakukan oleh Great British Sleep pada tahun 2018 menunjukkan bahwa orang yang memiliki kualitas tidur yang buruk mengalami masalah yang terkait dengan pola tidur yang buruk seperti kesulitan dalam mempertahankan perhatian, kurang motivasi dan kelelahan. ${ }^{23}$

Kualitas tidur yang buruk pada responden dapat menyebabkan gangguan konsentrasi. Hal ini sesuai dengan teori saat kita kekurangan waktu tidur, kita menyimpan suatu keadaan yang disebut sleep debt yang dapat diganti hanya melalui tidur. Hal ini diatur oleh suatu mekanisme dalam tubuh yang disebut sebagai sleep homeostat yang mengatur keinginan kita untuk tidur. Jika jumlah sleep debt besar, maka sleep homeostat akan memberitahukan pada kita bahwa kita perlu tidur lebih banyak. ${ }^{8}$ Orangorang yang mengalami kurang tidur akan mengalami rasa mengantuk yang berlebihan, kurang konsentrasi, refleks motorik yang buruk dan lambat. ${ }^{24,25}$ Hal ini sesuai dengan teori jika dihubungkan dengan hormonal, terutama melatonin dan serotonin yang sangat berperan dalam kondisi tidur, kadar kedua neurotransmitter ini akan meningkat untuk menciptakan kondisi mengantuk dan akan menurun seiring kondisi tidur mulai tercapai dan menjadi sangat rendah saat terbangun. Pada kondisi gangguan tidur melatonin dan serotonin terus meningkat untuk membuat tubuh beristirahat, tingginya kadar melatonin dan serotonin akan menimbulkan efek seperti mudah lemas, mengantuk, kesadaran yang berkurang, kecemasan dan gangguan fungsi kognitif yaitu konsentrasi. ${ }^{26}$

Tidur merupakan suatu kebutuhan dasar manusia yang sangat bermanfaat untuk mengembalikan kondisi tubuh pada keadaan yang semula, sehingga tubuh yang tadinya mengalami kelelahan akan menjadi segar kembali. Jika pemulihan terhambat maka akan menyebabkan organ tubuh tidak bisa bekerja dengan maksimal, akibatnya dampak yang ditimbulkan akibat buruknya kualitas tidur ialah penurunan daya tahan tubuh dan salah satu faktor yang menghambat belajar adalah faktor kesehatan, sehingga seseorang yang sakit atau kelelahan karena buruknya kualitas tidur akan sukar belajar dan menurunkan konsentrasi belajar. ${ }^{27}$

\section{Penutup}

\section{A. Kesimpulan}

Berdasarkan hasil penelitian tentang hubungan kualitas tidur dengan konsentrasi belajar mahasiswa Fakultas Kedokteran Universitas Baiturrahmah Padang angkatan 2018, maka dapat disimpulkan bahwa: Mahasiswa Fakultas Kedokteran Universitas Baiturrahmah Padang angkatan 2018 paling banyak memiliki kualitas tidur buruk yaitu 53 orang $(69,7 \%)$, yang paling banyak memiliki konsentrasi belajar buruk yaitu 42 orang $(55,3 \%)$. Terdapat hubungan kualitas tidur dengan konsentrasi belajar mahasiswa 
Fakultas Kedokteran Universitas Baiturrahmah Padang angkatan 2018. $\mathrm{P}=0,034<0,05$.

\section{B. SARAN}

mahasiswa Fakultas Kedokteran Universitas Baiturrahmah Padang untuk lebih bisa mengatur waktu dan memperhatikan kualitas tidur agar dapat berkonsentrasi dengan baik dalam beraktivitas. Peneliti selanjutnya agar dapat meneliti faktor-faktor yang lebih kompleks pengaruhnya terhadap konsentrasi belajar dengan sampel yang lebih banyak sehingga menghasilkan penelitian yang lebih beragam dan informasi yang lebih banyak tentang faktor yang berhubungan dengan konsentrasi belajar.

\section{Daftar Pustaka}

[1] Nilifda, H., Nadjmir, \& Hardisman. Hubungan Kualitas Tidur dengan Prestasi Akademik Mahasiswa Program Studi Pendidikan Dokter Angkatan 2010 FK Universitas Andalas. Jurnal Kesehatan Andalas. 2016; 004(1), 243-249.

[2] Lisiswanti R, Saputra O, Sari M, Zafirah N. Hubungan Antara Kualitas Tidur terhadap Hasil Belajar Mahasiswa Program Studi Pendidikan Dokter Fakultas Kedokteran Universitas Lampung . Juke.kedokteran.unila.ac.id. 2019 [cited 20 July 2019]. Available from: http://juke.kedokteran.unila.ac. id/index.php/agro/article/view/2253

[3] Fenny, Supriatmo. Hubungan Kualitas dan Kuantitas Tidur dengan Prestasi Belajar pada Mahasiswa Fakultas Kedokteran. Jurnal Pendidikan Kedokteran Indonesia; The Indonesian Journal of Medical Education, 2016; 5(3), 140-147.

[4] Dwi Mayasari F. Pengaruh Konsentrasi Belajar dan Motivasi Belajar Terhadap Hasil Belajar Siswa di SMK Negeri 1 Ngabang. Jurnal Pendidikan dan Pembelajaran. 2017 [cited 12 August 2019]. Available from: http://jurnal.untan.ac.id/index.php/jpdpb/article/vi ew/20651

[5] National Sleep Foundation's 2018 Sleep in America ${ }^{\circledR}$ Poll Shows Americans Failing to Prioritize Sleep | National Sleep Foundation [Internet]. Sleepfoundation.org. 2019 [cited 10 July 2019]. Available from: https://www. sleepfoundation.org/press-release/national-sleepfoundations-2018-sleep-americar-poll-showsamericans-failing

[6] Indirawati B N. Perbandingan Kualitas Tidur Mahasiswa yang Mengikuti UKM dan Tidak
Mengikuti UKM pada Mahasiswa Reguler Fakultas Ilmu Keperawatan Universitas Indonesia. Lib.ui.ac.id. 2012. Available from: http://lib.ui.ac.id/file?file=digital/20308112S42629-Perbandingan\%20kualitas.pdf

[7] Arisandi D. Hubungan Kualitas Tidur Terhadap Indeks Prestasi Kumulatif Pada Mahasiswa Fakultas Kedokteran Universitas Muhammadiyah Sumatera Utara. Repository.umsu.ac.id. 2017 [cited 8 December 2019]. Available from : http://repository.umsu.ac.id/bitstream/123456789 /4398/1/hubungan\%20kualitas\%20tidur\%20terha dap\%20indeks $\% 20$ prestasi $\% 20$ kumulatif $\% 20 \% 2$ 8ipk\%29\%20pada\%20mahasiswa\%20fakultas\%2 0kedokteran\%20universitas\%20muhammadiyah $\% 20$ sumatera\%20utara.pdf

[8] Sastrawan, I. M. A., \& Griadhi, I. P. A. (2017). Hubungan kualitas tidur dan daya konsentrasi mahasiswa program studi pendidikan dokter fakultas kedokteran Universitas Udayana. EJurnal Medika, 6(8), 1- 8. Retrieved from https://ojs.unud.ac.id/index.php/eum/article/view/ $33470 / 20280$

[9] Lumbantobing. 2004. Gangguan Tidur. Fakultas Kedokteran Universitas Indonesia, Jakarta, Indonesia.

[10] Widhiyanti K, Ariawati N, Rusitayanti N. Pemberian Back Massage Durasi 60 Menit Dan 30 Menit Meningkatkan Kualitas Tidur Pada Mahasiswa VI A PENJASKESREK FPOK IKIP PGRI Bali Semester Genap Tahun 2016/2017. Jurnal Pendidikan Kesehatan Rekreasi. 2017; 3(1): $9-18$.

[11] Hanifah E. Pengaruh Latihan Relaksasi Progresif Terhadap Penurunan Tingkat Insomnia Pada Lanjut Usia Di Panti Jompo Malang [skripsi]. Malang: Program Studi Fisioterapi Fakultas Ilmu Kesehatan Universitas Muhammadiyah Malang; 2018.

[12] National Sleep Foundation, 2006. Sleep-Wake Cycle ;"Its Physiology an Impact on Health". Http://www.sleepfoundation.or. Diakses pada 5 desember 2019).

[13]Lai et, al. 2001. Hypertension and its Related Factors in Taiwanese Elderly People. Yale Journal of Biology and Medicine. 74 (2): 80 -94.

[14] Sindo.. Insomnia pada Remaja.2008. www.okezonelifestyle.com (3 Desember 2019).

[15] Mote T. Effects of Depression on Sleep. 2010. [cite 28 Jully 2019] Avaiable from : Http://Mote.com/article/69548-effectsdepression-sleep

[16] Soong J. Side sleeper?Back sleeper? Stomach sleeper? How you sleep may hold clues o how well you sleep., Soong. 2011. [cite 27 Jully 2019]Available from: Http://www.Soong.com/ sleep-disorders/features/sleep-position-andsleepquality 
[17] Preisegolaviciute E, Leskauskas D, Adomaitiene V. Associations of quality of sleep with lifestyle factors and profile of studies among Lithuanian students. Medicina (Kaunas). 2010;46(7):482-9.

[18] Rahmadi FM. Hubungan Kualitas Tidur Terhadap Konsentrasi Mahasiswa Fakultas Kedokteran Universitas Muhammadiyah Palembang Sebelum Mengikuti Ujian [skripsi]. Palembang: Fakultas Kedokteran Universitas Muhammadiyah Palembang; 2017.

[19]Fauzan R. Gambaran Kualitas Tidur pada Mahasiswa Kedokteran Fakultas Kedokteran Universitas Sumatera Utara Tahun Akademik 2013/2014 [skripsi]. Medan: Fakultas Kedokteran Universitas Sumatera Utara; 2013.

[20] Sofiyya I. Hubungan Kualitas Tidur dengan Konsentrasi Belajar pada Remaja di Yogyakarta [skripsi]. Yogyakarta: Jurusan Kesehatan Gizi UGM; 2015.

[21] Hermawan, D.I. (2014). Teknik Permainan Edukatif untuk Meningkatkan Konsentrasi Belajar Siswa. Skripsi strata satu, Universitas Sebelas Maret. Diakses 4 Desember 2019. https://digilib.uns.ac.id

[22]Lestari g, Rahmawaty I. Hubungan Antara Olahraga Futsal Dengan Konsentrasi. Karyailmiah.unisba.ac.id. 2016 [cited 14 November 2019]. Available from: http://karyailmiah.unisba.ac.id/index.php/dokter/a rticle/ view/1170/pdf

[23] Kyle, S. 2012. Sleepiness, fatigue and impaired concentration. Diperoleh Tanggal 12 Desember 2019 dari https://www.sleepio.com/articles/i nso mnia/sleepiness-fatigueandimpairedconcentration

[24] Agoes, A; Lestari, R; Dewi,P,N. Pengaruh Senam Otak Terhadap Peningkatan Konsentrasi Belajar Siswa (umur 11-12 Tahun) di SDN Nambangan Kidul 05 Kecamatan Jiwan Kabupaten Madiun. Majalah Kesehatan FKUB. 2010.

[25] Malawi, I dan Tristiar, AA. (2013). Pengaruh Konsentrasi Belajar dan Kemampuan Berpikir Kritis terhadap Prestasi Belajar IPS Siswa Kelas V SDN Manisrejo I Kabupaten Magetan. Jurnal Pendidikan Dasar dan Pembelajaran, Vol 3, No. 2, 2013.

[26] Hall MA, Uysse DAJB, Owell PEDN.Ofzinger ERICAN, Ouck PAH, Eynolds CHFR. 2000. Symptoms of Stress and Depression as Correlates of Sleep in Primary Insomnia. Psychosomatic Medicine, 6 December 2019. 227-230

[27] Patlak, M. 2005. Your Guide to Healthy Sleep. U. S. Department of Health and Human Services. http://www.nhlbi.nih.gov/health/ public/sleep/healthy_ sleep.pdf. diakses 12 Desember 2019.

Email : heme@unbrah.ac.id 